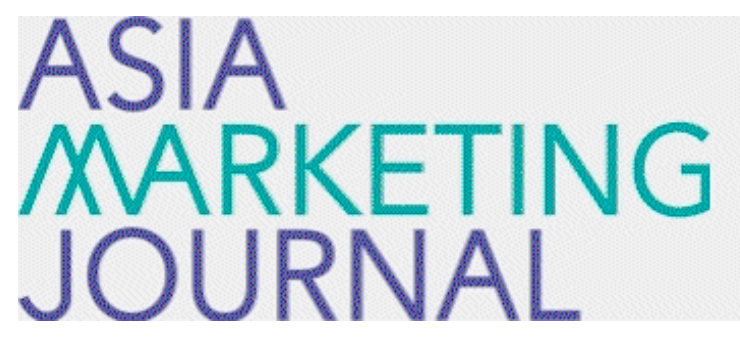

ASIA MARKETING JOURNAL

Volume 16 | Issue 4

Article 4

$1-31-2015$

\title{
Sales People as Emotional Laborers
}

JungKun Park

Weon Sang Yoo

Brian Rutherford

Follow this and additional works at: https://amj.kma.re.kr/journal

Part of the Marketing Commons

\section{Recommended Citation}

Park, JungKun; Yoo, Weon Sang; and Rutherford, Brian (2015) "Sales People as Emotional Laborers," Asia Marketing Journal: Vol. 16 : Iss. 4 , Article 4.

Available at: https://doi.org/10.15830/amj.2015.16.4.39

This Article is brought to you for free and open access by Asia Marketing Journal. It has been accepted for inclusion in Asia Marketing Journal by an authorized editor of Asia Marketing Journal. 


\title{
Sales People as Emotional Laborers: Psychological And Behavioral Outcomes*
}

\author{
JungKun Park ${ }^{* *}$ \\ Weon Sang Yoo*** \\ Brian Rutherford $\mathbf{w}^{* * * *}$
}

\begin{abstract}
Ever since Hochschild (1983) introduced the concept of emotional labor in the workplace, it has constantly interested researchers due to its impact on employees' well-being as well as organizational outcomes. However, a thorough understanding of emotional labor and its relationship with various outcomes in sales people is not yet realized. In a systemic approach to the concept using quantitative methods is still necessary. The present study treats emotional labor as two factors (e.g. emotive dissonance and emotive effort). The psychological and behavioral outcomes of each sub-construct of emotional labor are investigated within a parsimonious framework. The findings suggest that emotional dissonance affected job satisfaction, while emotive effort had a significant influence on emotional exhaustion and job performance.
\end{abstract}

Key words: Emotional Labor, Emotive Dissonance, Emotive Effort, Emotional Exhaustion, Job Satisfaction, Job Performance

\section{Introduction}

Emotions play an integral part in general hu- man decision making processes (Frijda 1986). In work place settings, the roles of emotions have recently garnered increasing attention from marketing researchers and service man-

\footnotetext{
* The research reported is funded by the Social Science Korea (SSK) Research Grant of the National Research Foundation of Korea, and the authors would like to thank the National Research Foundation of Korea for supporting their research project (Project No. \#B00096).

** Ph.D. (The University of Tennessee, Knoxville), Associate Professor of Retail Management, College of Technology, University of Houston(jpark21@central.uh.edu)

*** Ph.D. (University of British Columbia), Associate Professor of Marketing, Korea University Business School, (wyoo@korea.ac.kr), Corresponding Author

**** Ph.D. (Georgia State University), Assistant Professor of Sales and Selling Management, Department of Marketing and Professional Sales, Kennesaw State University(bruther1@kennesaw.edu)
} 
agement (Fisher and Ashkanasy 2000). In the past, the notion of emotion was treated in the broad sense and at most considered an interrupter of rational decision making processes (Weber 1981). However, recent literature has delineated emotions of various types and identified both positive and negative effects of utilizing emotions in the workplace (Kruml and Geddes 2000). One of the specific topics that has drawn interest from organizational marketing researchers is emotional labor.

The term emotional labor, first coined by Hochschild (1983) and it is defined as "the management of feeling to create a publicly observable facial and bodily display." In her empirical study on flight attendants, she asserted that there exist common expectations or "feeling rules/display rules" that should be abided by service providers when dealing with emotions elicited during interaction for service delivery. For example, employees in retail settings who was upset for personal reasons would be re- $^{-}$ quired to display smiles to customers in the store regardless of their true emotional state. Although it may depend on the nature of the job or retail sector, it is commonly accepted that the general display rule for employees is to provide "service with a smile" (Glomb and Tews 2004; Pugh 2001).

Using appropriate emotions was indicated to be critical element in customer-employee interaction (Dormann et al. 2002). Well-managed emotions or positively expressed emotions are known to effect value-added outcomes such as customer satisfaction (Ashkanasy et al. 2002; Menon and Dube 2000). Given that satisfaction is positively associated with customer loyalty (Zeithaml et al. 1996), which is considered an organization's ultimate aim (Reichheld 1996), investigating emotional labor is worthwhile. In addition, studies utilizing emotional contagion theory support positive association between frontline employees' positive emotional display and customers' future return intention (HennigThurau et al. 2006; Pugh 2001). Emotional contagion theory explains the process of people's tendency to automatically mimic and synchronize facial expressions, vocalizations, and movements with those of another person and, consequently, to converge emotionally (Hatfield et al.1994). In other words, customers who are treated by front-line employees with "managed hearts" are likely to be satisfied with the service and return.

While emotional labor delivers value added outcomes to an organization, it requires employees to perform "external controls" and "divisions of labor" just like physical labor (Mastracci et al. 2006). Hochschild (1983) contended that expressing or experiencing a "false nature" of imposed feelings could be deleterious to service workers. Accordingly, emotional labor has been linked to potential psychological strains such as emotional exhaustion (MartinexIngo et al. 2007) and job dissatisfaction (Pugliesi 1999) at the individual level. As for the link 
between the behavioral aspect of job outcomes and emotional labors, Diefendorff and Gosserand (2003) proposed the negative relationship between job performance and emotional labor. In addition, it was asserted that emotional labor should be an important component of the job performance appraisal process (Mastracci et al. 2006).

Despite its substantial impacts on employees' psychological well-being and organizational outcomes, emotional labor has rarely been examined in a systematic manner within a framework including its consequences. Several empirical studies on emotional labor were conducted in the 1990s, but no consensus has yet been achieved concerning its nature and outcomes (Glomb and Tow 2004). To fill the research gap, this present study aims to achieve the following research objectives: (1) to provide a parsimonious framework which both includes psychological and behavioral outcomes of utilizing emotional labor in the U.S. frontline retail sales employee context; (2) to identify different forms of emotional labor using the conceptualization by Kruml and Geddes(2000) (e.g. emotive effort, emotive dissonance); and, (3) to investigate their influences on psychological (e.g. emotional exhaustion, job satisfaction) and behavioral outcomes (e.g. job performance) of retail sales employees.

\section{Literature Review}

\subsection{Emotional Labor}

Emotions are feelings which are experienced, interpreted, reflected on, expressed, and managed (Thoits, 1989; Mills and Kleinman, 1988). Emotional labor is defined by Hochschild as "the management of feeling to create a publicly observable facial and bodily display" (1983, p.7). The literature indicates that emotional labor can have both positive and negative consequences. It can lead to negative consequences such as burnout (Kahn, 1993; Morris \& Feldman, 1996) and job dissatisfaction (Grandey, 1999; Wharton, 1993). On the other hand, some studies have suggested positive consequences for both organizations and individuals. Positive consequences include ensuring task effectiveness and service quality for the organization and increased self efficacy and psychological well-being for the employee (Ashforth \& Humphrey, 1993; Cho, et al., 2013).

Ever since sociologist Arlie Hochschild (1983) introduced the notion of emotional labor, the topic has continued to gain increased attention among researchers. She took a dramaturgical perspective of a service setting, in which service is compared to a stage and employees are seen as actors. The depth and direction of interaction between actors and audiences are decided by "display rules." Provided that a de- 
sirable goal of service interaction is to satisfy customers emotionally (Zapf et al. 2001), it is expected that employees control their emotions to an organizationally preferable level. Hochschild (1983) asserted that there exists three forms of emotional reacting strategies when a service provider confronts emotional dissonance, which is experienced when expressed emotions and truly felt internal feelings do not match. Those three reacting strategies include surface acting, active deep acting, and passive deep acting. Surface acting corresponds to a situation in which an employee alters his/her outward emotional expressions to conform to organization norms, but does not change inner feelings. In comparison, active deep acting occurs when service providers put effort into shifting outward emotional expression as well as to manage their inner feelings by regulation processes. Also, passive deep acting is distinguished from the previous two methods in that a service provider spontaneously feels and expresses emotions appropriate to a situation.

Although Hochschild (1983) paved the way for research into emotional labor, subsequent researchers pointed out the incompleteness of operationalization of the concept and called for elaboration (Morris and Feldman 1996). The term emotional labor was redefined as "the effort, planning, and control needed to express organizationally desired emotion during interpersonal transactions." They conceptualized emotional labor as four sub-constructs of frequency, duration of emotional display, variety of emotions required, and emotional dissonance (Morris and Feldman 1997).

Meanwhile, other researcher including Krumel and Geddes (2000) critiqued content validity of the first three dimensions (frequency, duration, and variety) contrived by Morris and Feldman (1996) and attempted reconceptualization of the construct. Krumel and Geddes (2000) developed scales for emotional labor based on the three types of acting. Through a series of factor analyses, they concluded that there exist two different dimensions of emotional labor, (1) emotive dissonance and (2) emotive effort, which reflect the original content of Hochschild's acting perspective (1983). Emotive dissonance refers to the size of discrepancy between one's actual feeling and the emotions required to express on the job. The term was interchangeably used with emotional dissonance in another study (Morris and Feldman 1996). Emotive effort indicates the degree to which employees actively try to change their internal feelings to match those they must express to their customers. In light of Hochschild's work (1983), the dimension of emotive dissonance captures surface acting and passive deep acting as two opposite ends of a continuum. When employees have the higher the degree of surface acting, they usually have the higher the emotive dissonance. On the other hand, active deep acting corresponds to the dimension of emotive effort. The emotive effort dimension of emotional labor captures employ- 
ees' efforts when they are engaged in deep acting.

Although past studies investigated the relationship between emotional labor and job outcomes (Pugliesi 1999; Zapf and Holz 2006), no research attempted to observe differentiating effects of the two dimensions of emotional labor (emotive dissonance and emotive efforts) on job outcomes. The present study adopts the two dimensional conceptualization of emotional labor developed by Krumel and Geddes (2000), and assumes that employees would react distinctively on the outcomes of emotional labor as suggested.

As for the link between emotional labor in general and its outcomes, mixed findings were found. Pugiliesi (1999) stated that the outcomes of emotional labor are not necessarily negative. Some of the existing literature reports that emotional labor could influence increasing levels of self-accomplishment, sense of control, and job satisfaction when job autonomy was granted. On the other hand, however, it could also lead to low levels of job satisfaction, emotional exhaustion, and psychological distress. Lewig and Dollard (2001) asserted that emotional labor can increase task effectiveness by making employee-customer relationships more predictable, but can be dysfunctional due to the emotional dissonance component. Ashforth and Humphrey (1993) also acknowledged both positive and negative effects of emotional labor in that it can contribute to satisfying employees' need for self-expression but also produce emotive dissonance and self-alienation. In a recent study on emotional labor of front - line employees, Kinman (2009) also predicted association between emotional labor and a series of negative job outcomes such as psychological distress, work-life conflict, and low level of job satisfaction.

We propose that the mixed findings on the consequences of emotional labor reflect different contributions of the two independent dimensions of emotional labor (emotive dissonance and emotive effort) on the results.

\subsubsection{Emotive Dissonance}

Emotive dissonance is defined as "the structural discrepancy between which emotions need to be displayed and what is really felt" (Bakker and Heuven 2003). A closer look at drawbacks of emotional labor reveals they are mostly related to emotive dissonance or emotional dissonance rather than emotive effort. For example, Zapf et al. (2001) stated that "display rules" for employees do not necessarily cause psychological stress, but may become so via emotional dissonance. Morris and Feldman (1996, 1997) asserted that emotional dissonance is associated with emotional exhaustion and job dissatisfaction. Gross (1998) also argued that emotional dissonance can contribute to generating physiological and psychological dysfunctionality. Subsequently, other researchers found a positive association between emotional dissonance 
and ill-health (Brotheridge and Grandey 2002; Grandey 2000).

The reason why employees want to reduce the level of emotional dissonance might be explained by conservation-of-resource theory (Hobfoll 1989). The theory proposes a stressor as a loss of a valuable resource and, in turn, valuable resource is defined as a source which increases the likelihood of experiencing pleasure. Emotional dissonance is likely to have negative impacts on psychological and behavioral job outcomes because self- regulating processes can be stressors because it creates an unpleasant state just like cognitive dissonance (Festinger 1956).

The current research hypothesizes that emotive dissonance or equally termed emotional dissonance results in negative job outcomes in general.

\subsubsection{Emotive Effort}

As mentioned earlier, emotive effort is concerned with active deep acting strategies, with which employees alter their actual inner feelings to meet the required feeling state. And service workers intentionally spend time and energy in order to do that. Hochshild (1983) originally contended that sustaining a certain level of emotion requires one to expend energy, which finally could result in psychological and physiological drains. According to her research, employees who cannot separate their "true self" and "acted self" are more vulnerable to emotional exhaustion. Maslach (1981) also found that individuals are more susceptible to emotional exhaustion when they invest more emotion in the enactment of their helping roles. Therefore, the present study hypothesizes that emotive effort is positively associated with emotional exhaustion, job satisfaction, and job performance, which are considered to be important job outcomes. The definitions and detailed discussion of each term follow.

\subsection{Emotional Exhaustion}

Emotional exhaustion is one of the three dimensions of burnout and is often the primary aspect of salesperson burnout examined (e.g. Rutherford et al. 2009; Hamwi et al. 2011; Hollet-Haudebert 2011; Shepherd et al. 2011). Emotional exhaustion is defined as a state of depleted energy caused by excessive emotional demands made on people interacting with customers or clients (Saxton, Phillips, and Blakeney 1991). Emotional exhaustion is one of the most frequently cited consequences of emotional labor (Hochschild 1983; Wharton 1999; Morris and Feldman 1996; Pugliesi and Shook 1997; and Kruml \& Geddes 2000). The initial research on emotional labor emphasized its negative consequences, such as self estrangement (Hochschild 1983), increased psychological distress and symptoms of depression (Pugliesi and Shook 1997; Wharton 1999) and emotional exhaustion (Morris and Feldman, 1996). This 
study focuses on investigating which dimension of emotional labor is more likely to result in emotional exhaustion. Past research has consistently demonstrated that different dimensions of emotional labor have different impacts on emotional exhaustion.

Specifically speaking, research results showed that both emotive effort and emotional dissonance are positively associated with emotional exhaustion, Morris and Feldman (1997) found that dissonance and emotional exhaustion are positively associated. Although this result did not confirm Hochschild's view that surface acting protects employees from becoming emotionally burn-out, consistent results were reported in other studies (Grandey 2000; and Kruml \& Geddes 2000). The role conflict theory also suggests a positive relationship between the two constructs (Abraham 1998).Based on the aforementioned discussion, the following hypotheses were formulated.

H 1: Emotive dissonance is positively related to emotional exhaustion.

H2: Emotive effort is positively related to emotional exhaustion.

\subsection{Job Satisfaction}

Job satisfaction is defined as "a pleasurable or positive emotional state resulting from the appraisal of the job" (Locke 1976). It is logical to infer that the appraisal of the job is related to one's perception of the job (perceived job performance) and emotions related to or $\mathrm{re}^{-}$ sultant from the job (emotional exhaustion). Both positive (Ashforth and Humphrey 1993) and negative (Pugliesi and Shook 1997; Pugliesi 1999) relationships were found between emotional labor and job satisfaction. As discussed earlier, no consensus has been reached on whether job satisfaction was under direct influence of emotional labor, or if the negative/positive emotions induced by emotional labor mediate its effect on job satisfaction. Grandey et al. (2005) argued a negative relationship between emotional labor and job satisfaction. Morris and Feldman (1997) also argued that emotive dissonance that leads to emotional exhaustion, and in the end, results in low job satisfaction. On the other hand, Kruml and Geddes (2000) stated that by deep acting, the employee might be rewarded with personal accomplishment that leads to job satisfaction. Further, the linkage between emotional exhaustion and job satisfaction is document within the retail-based sales literature (Jaramillo, Mulki, and Locander 2006: Karatape and Tekinkus 2006; Rutherford et al. 2011a; Rutherford et al. 2011b; Oh, et. al., 2014). Based on the information in previous sections and the aforementioned background, the following hypotheses were generated.

H3: Emotive dissonance is negatively related to job satisfaction.

H4: Emotive effort is positively related to 
job satisfaction.

H5: Emotional exhaustion is negatively related to job satisfaction.

\subsection{Job performance}

Sales researchers frequently examine predictors of job performance (e.g. DeConinck 2011; Jaramillo et al. 2011; Yang et al. 2011). Employee job performance is defined as behaviors that are (1) pertinent to organizational goals, and (2) under the control of individual employees (Campbell et al. 1992). The definition coincides with the concept that emotional labor (employees' performance) is regulated by the organization's display rules, yet employees can control the strategies used when demonstrating the required emotions.

Despite the fact that emotional exhaustion can be one of the negative consequences of performing emotional labor, past research also discovered positive outcomes of emotional labor. For instance, research indicated that performing emotional labor can enhance self-efficacy and self expression (Pugliesi 1999) that leads to task effectiveness. This study proposes that if one is able to regulate one's inner feelings to be in tune with the desired emotions and demonstrate the emotions during job performance, it will result in positive perception of one's job performance and job satisfaction. Grandey (2003) also found that when deep acting employees actually try to feel what is expected their neg- ative moods and reactions are less likely to be leveled. On the other hand, by merely expressing or faking the required emotions during job performance will lead to negative perception of one's job performance (Grandey et al. 2005). In addition, Diefendorff and Gosserand (2003) suggested that emotive dissonance is negatively related to job performance.

The literature shows that emotional exhaustion is negatively associated with job performance (Singh et al., 1994; Wright \& Bonett, 1997; Wright \& Cropanzano, 1998). Emotionally exhausted employees have reduced resources and energy available, thereby leading to diminished efforts at work (Singh et al., 1994). Wright and Cropanzano (1998) found that emotionally exhausted employees would use avoidance or withdrawal coping mechanisms, including reduced job performance, to help restore or minimize their lost resources. Similarly, Wright and Bonnet (1997) suggested that intense emotional exhaustion would interfere with effective job performance. In addition, it is widely known that job satisfaction is widely accepted as a key antecedent of customer loyalty (Zeithaml et al. 1996). Hence, the following hypotheses were formulated.

H6: Emotive dissonance is negatively related to job performance.

H7: Emotive effort is positively related to job performance.

H8: Emotional exhaustion is negatively re- 
〈Figure 1〉 Proposed Conceptual Model for Emotional Labor and Outcome Variables

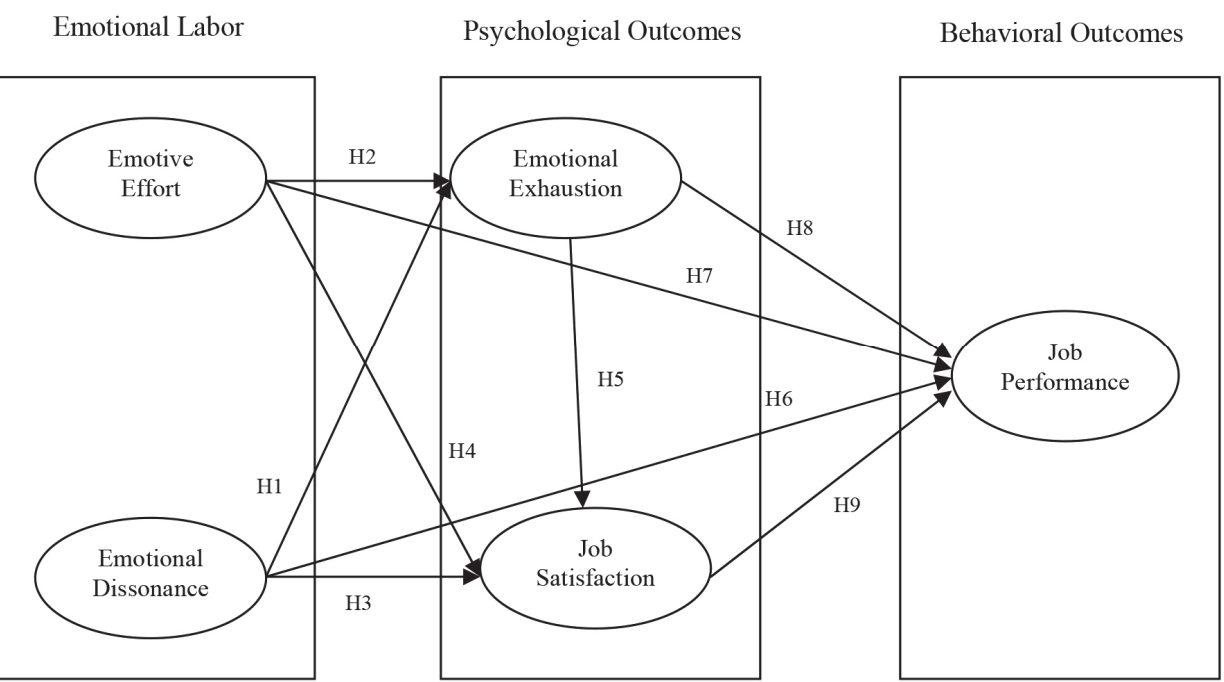

lated to job performance.

H9: Job satisfaction is positively related to job performance.

Overall, the conceptual framework with all the hypotheses proposed is presented in Figure 1.

\section{Methodology}

\subsection{Data Collection and Sample Characteristics}

To conduct this research, data collection involved an online survey, which was performed via an independent marketing company with a nationwide pool of retail employees. A total of 1,000 randomly selected potential respondents were invited to participate in the study. The obtained usable respondents were 186. The response rate was $18.6 \%$.

The retail employee who participated in the study was 26 years of age on average. Twothirds of the respondents had a college degree, while the remaining 18\% had only a high school degree. The male respondents comprised $37.3 \%$ and $62.7 \%$ of the employees were females.

\subsection{Measurements}

All of the constructs were measured with seven-point Likert-type scales ( $1=$ strongly disagree, $7=$ strongly agree). Four items for emotive effort and 2 items for emotive dissonance were adopted from the study conducted by Kruml and Geddes (2000). To measure 
emotional exhaustion, 9 items were also adopted from the previous study by Maslach and Jackson (1981). Five items were used to measure job satisfaction taken from past research by Hackman and Oldham (1975). Job performance was measured with 4 items adopted from a previous study (Pettit et al. 1997).

\section{Results}

\subsection{Measurement Model}

A confirmatory factor analysis was first performed with a maximum likelihood estimation method to assess convergent and discriminant validity. This is the initial phase of the twostep approach recommended by Anderson and Gerbing (1988). After first running CFA, items with low multiple square correlations (less than 0.03) and low factor loadings (less than 0.05) were deleted to improve internal consistency. Table 1 provides values for factor loadings, item reliabilities, Croanbach's alphas, and the average of variance extracted (AVE). The values of Cronbach's alpha in each construct exceeded the suggested cut-off of .70 (Nunnally 1978). The reliabilities were the following: Emotive dissonance $=0.76$; emotive effort $=0.77$; emotional exhaustion $=0.87$; job satisfaction $=0.82$; job performance $=0.84$. The average variance extracted (AVE) for the constructs with mul- tiple measures all exceed the minimum of .50 suggested by (Fornell and Larcker 1981). All of the AVE values for each construct exceeded the minimum criterion. The average of variance extracted (AVE) of each construct was larger than shared variances, which supported discriminant validity of the measurement model. The fit-statistics for the measurement model reached the recommended levels $\left(\chi^{2}=88.47(\mathrm{df}=52), \mathrm{p}=0.00 ; \quad \chi^{2} / \mathrm{df}=1.71 ;\right.$ CFI $=0.96 ; \quad \mathrm{NFI}=0.91 ; \quad \mathrm{GFI}=0.92 ; \quad$ RMSEA $=0.069$ ). The suggested acceptance level of a good fit model requires that the obtained CFI, NFI, and GFI should be greater than or equal to .90. The recommended value of RMESA is in the acceptable range from 0.05 to 0.08 (Hair 2006).

\subsection{Structural Equation Model and Hypotheses Testing}

As a subsequent step, the structural equation model was tested to examine the proposed model. The model produced acceptable goodness-of-fit statistics (Table 3). Overall fit of the structural model was initially examined utilizing the $\chi^{2}$ statistic. In order to compensate for the sensitivity of $\chi^{2}$ statistic to sample size, other measures of goodness-of-fit, such as comparative fit index (CFI), normalized fit index (NFI), goodness of fit index (GFI), and root mean square error of approximation (RMESA) were additionally investigated. 
$\langle$ Table 1〉 Reliabilities and confirmatory factor analysis properties

\begin{tabular}{|c|c|c|c|}
\hline Factors & $\begin{array}{l}\text { Factor } \\
\text { Loading }\end{array}$ & $\begin{array}{l}\text { Cronbach's } \\
\text { Alphas }\end{array}$ & AVE \\
\hline Emotional Effort & & 0.77 & 0.55 \\
\hline $\begin{array}{l}\text { I work at conjuring up the feelings I need to show to } \\
\text { customers. }\end{array}$ & 0.62 & & \\
\hline $\begin{array}{l}\text { I try to change my actual feelings to match those that } \\
\text { I must express to customers. }\end{array}$ & 0.92 & & \\
\hline $\begin{array}{l}\text { When working with customers, I attempt to create certain } \\
\text { emotions in myself that present. }\end{array}$ & 0.66 & & \\
\hline Emotional Dissonance & & 0.76 & 0.66 \\
\hline I show the same feelings to customers that I feel inside. & 0.63 & & \\
\hline $\begin{array}{l}\text { The emotions in myself that present the image my company } \\
\text { desires. }\end{array}$ & 0.95 & & \\
\hline Emotional Exhaustion & & 0.87 & 0.69 \\
\hline I feel emotionally drained from my work. & 0.85 & & \\
\hline I feel burned out from my work. & 0.91 & & \\
\hline I feel like I'm at the end of my rope. & 0.71 & & \\
\hline Job Satisfaction & & 0.82 & 0.61 \\
\hline People on this job often think of quitting (R). & 0.91 & & \\
\hline I frequently think of quitting this job (R). & 0.69 & & \\
\hline Most people on this job are very satisfied with their jobs. & 0.73 & & \\
\hline Job Performance & & 0.84 & 0.75 \\
\hline $\begin{array}{l}\text { How would you rate the quality of your own performance } \\
\text { in your job? }\end{array}$ & 0.98 & & \\
\hline $\begin{array}{l}\text { How would you rate the quantity of your own performance } \\
\text { in your job? }\end{array}$ & 0.73 & & \\
\hline
\end{tabular}

The produced statistics of the proposed model revealed that the model was fairly well fitted; the data displayed the following values: $\chi^{2}=$ 88.47 ( $\mathrm{df}=52$ ), $\mathrm{p}=0.00 ; \quad \chi^{2} / \mathrm{df}=1.71 ; \mathrm{CFI}$ $=0.96 ; \mathrm{NFI}=0.91 ; \mathrm{GFI}=0.92 ; \mathrm{RMSEA}=0.069$ ). This result suggests a good fit for the proposed model. Simple statistics including means, standard deviation, and correlations of the proposed model are summarized in Table 2.

Table 3 summarizes the results from testing the hypotheses. The results of the path $\mathrm{co}^{-}$ efficients and t-statistics show all the hypotheses to be supported except H1, H4, and H6. Hypothesis1, which predicted a positive relationship between emotive dissonance and emotional exhaustion, was not supported. Hypothesis 2, which hypothesized a positive influence of emotive effort on emotional exhaustion, was supported $(\gamma=0.546, t=3.494, p<0.01)$. As expected in hypothesis 3 , emotive dissonance significantly affected job satisfaction in a negative direction $(\gamma=-0.326, \mathrm{t}=-2.359, \mathrm{p}<0.05)$. 
〈Table 2〉 Construct Means, Standard Deviations, and Correlations

\begin{tabular}{|c|c|c|c|c|c|c|c|}
\hline & $\begin{array}{c}\text { Emotional } \\
\text { Effort }\end{array}$ & $\begin{array}{c}\text { Emotional } \\
\text { Dissonance }\end{array}$ & $\begin{array}{c}\text { Emotional } \\
\text { Exhaustion }\end{array}$ & $\begin{array}{c}\text { Job } \\
\text { Satisfaction }\end{array}$ & $\begin{array}{c}\text { Job } \\
\text { Performance }\end{array}$ & Mean & SD \\
\hline $\begin{array}{c}\text { Emotional } \\
\text { Effort }\end{array}$ & 0.742 & 0.812 & & & & 4.52 & 1.38 \\
\hline $\begin{array}{c}\text { Emotional } \\
\text { Dissonance }\end{array}$ & 0.007 & 0.121 & 0.830 & & & 4.42 & 1.14 \\
\hline $\begin{array}{c}\text { Emotional } \\
\text { Exhaustion }\end{array}$ & $0.310^{* *}$ & $-0.169^{*}$ & $-0.583^{* *}$ & 0.781 & & 2.90 & 1.64 \\
\hline $\begin{array}{c}\text { Job } \\
\text { satisfaction }\end{array}$ & -0.111 & -0.119 & $-0.307^{* *}$ & $0.313^{* *}$ & 0.866 & 6.02 & 0.87 \\
\hline $\begin{array}{c}\text { Job } \\
\text { Performance }\end{array}$ & -0.233 & 0.69 & 1.60 \\
\hline
\end{tabular}

Note: ${ }^{*} p<0.05,{ }^{* *} p<0.01$; Square root of average variance extracted (AVE) is shown on the diagonal of the matrix: inter-construct correlations is shown off the diagonal.

However, emotive effort did not significantly influence job satisfaction, which led to a rejection of hypothesis 4 . The significant path loading from emotional exhaustion to job satisfaction confirmed hypothesis $5(\gamma=-0.786$, $\mathrm{t}=-7.536, \mathrm{p}<0.01)$. However, emotive dissonance was not influential in predicting job performance, which resulted in a rejection of hypothesis 6 . Hypothesis 7, which predicted a positive relationship between emotive effort and job performance, was supported as expected $(\gamma=0.209, t=2.521, p<0.05)$. Likewise, the negative relationship between emotional exhaustion and job performance was confirmed by supported hypothesis 8 ( $\gamma=-0.133, \mathrm{t}=$ $-1.901, \mathrm{p}<0.05)$. Hypothesis 9, which predicted

〈Table 3〉 Structural Models Results

\begin{tabular}{|c|l|c|c|c|}
\hline Hypothesis & \multicolumn{1}{|c|}{ Structural Path } & Coefficients & T-value & $\begin{array}{c}\text { Test } \\
\text { Results }\end{array}$ \\
\hline H1 & Emotive Dissonance $\rightarrow$ Emotional Exhaustion & -0.185 & -1.39 & Rejected \\
\hline H2 & Emotive Effort $\rightarrow$ Emotional Exhaustion & 0.546 & $3.494^{* *}$ & Accepted \\
\hline H3 & Emotive Dissonance $\rightarrow$ Job Satisfaction & -0.326 & $-2.359^{*}$ & Accepted \\
\hline H4 & Emotive Effort $\rightarrow$ Job satisfaction & 0.232 & 1.478 & Rejected \\
\hline H5 & Emotional Exhaustion $\rightarrow$ Job Satisfaction & -0.786 & $-7.536^{* *}$ & Accepted \\
\hline H6 & Emotive Dissonance $\rightarrow$ Job Performance & 0.032 & 0.461 & Rejected \\
\hline H7 & Emotive Effort $\rightarrow$ Job Performance & 0.209 & $2.521^{*}$ & Accepted \\
\hline H8 & Emotional Exhaustion $\rightarrow$ Job Performance & -0.133 & $-1.901^{*}$ & Accepted \\
\hline H9 & Job Satisfaction $\rightarrow$ Job Performance & 0.106 & $1.803^{*}$ & Accepted \\
\hline Goodness-of-fit: $\mathrm{X}_{52}^{2} 88.47=0.00 ;$ CFI $=0.96 ;$ NFI $=0.91 ;$ GFI $=0.92 ;$ RMSEA $=0.069$ & \\
\hline
\end{tabular}

Note: *p<0.05, **p $<0.01$ 
a positive relationship between job satisfaction and job performance was supported $(\gamma=0.106$, $t=1.803, p<0.05)$

\section{Conclustions and Discussion}

Generally speaking, emotional labor has been considered as a stressor, just like time pressure or role conflict, which service workers have to deal with in the workplace. Emotional labor clearly has negative aspects in terms of its influences on employees' psychological and physiological soundness. However, the current study extends a growing body of literature on emotional labor by suggesting possibilities that emotional labor can be advantageously utilized by employees so as to achieve organizational outcomes effectively. Based on the work by Kruml and Geddes (2000), emotional labor was conceptualized as having two different types of emotive dissonance and emotive effort in the present study. This conceptualization was chosen because it positively reflected the original mechanism of the concept by Hochschild (1983). Then influences of emotive dissonance and emotive effort on the employees' psychological states (e.g. emotional exhaustion and job satisfaction) and behavioral outcomes (e.g. job performance) were investigated utilizing the structural equation model. The conceptual framework was formulated in advance. This aspect of the current study is another valuable addition to the existing literature because a systemic approach to the concept is necessary (Glomb and Tews 2004).

The analysis results reveal that emotive dissonance and emotive effort were distinguished in their nature and impact on psychological and behavioral outcomes. First, the reliability of emotional labor as one construct was extremely low, with a value of 0.038 . In addition, when the four-factor model was analyzed instead of a five-factor model treating emotional labor as one construct at the measurement model phase, the model was not successfully loaded with inadequate model fit indices. This implies that future studies should treat emotional labor as having the two different qualities as suggested (Kruml and Geddes 2000).

To summarize the study results, emotive dissonance had a direct influence on job satisfaction in the negative direction, but not on emotional exhaustion and job performance. One probable reason for no direct association between emotive dissonance and emotional exhaustion could be attributed to the nature of emotion. In other words, unlike cognitive dissonance, emotive dissonance may not necessarily be related to the unpleasant state depending on a particular situation in job settings, because other factors such as the level of employee-customer interaction or job involvement or required job responsibility could affect the path between emotive dissonance and emotional exhaustion. For in- 
stance, the unpleasant feeling caused by emotive dissonance could be offset by a pleasant interaction between a service worker and a customer or by compensation of salary. This is subject to further investigation. On the other hand, emotive effort directly impacted on emotional exhaustion and job performance, but not on job satisfaction. This indicates that emotive effort may be related to task effectiveness rather than emotive dissonance as discussed earlier. In addition, the positive association between emotive effort and emotional exhaustion implies that sustaining a certain level or type of emotion could be tiring for service workers.

The present study delivers some managerial implications. First, the reported differential effects of emotive dissonance and emotive effort on the psychological and behavioral outcomes suggest that the emotive effort variable should be weighted in the job performance appraisal process when including emotion work components. Second, the negative significant relationship between emotive dissonance and job satisfaction suggests that organizational support programs such as worksite health promotion, which can enhance other aspects of job satisfaction, should be provided in order to decrease the negative effect of emotive dissonance on employees' psychological well-being.

Despite its valuable contributions to the literature, this study also had some limitations. First, the present study was conducted without considering specific types of jobs. The level, form, and duration of emotional work required by an organization may vary by job types; thus, the effect strength and direction of emotive dissonance and emotive effort on organizational outcomes may not be consistent from one job to another. Second, the level of an employee should also be examined in future studies because a novice or entry level employee could be more influenced by performing emotion work regardless of its type compared to an experienced worker.

〈Received August 18. 2013〉

〈Accepted January 5. 2015〉

\section{References}

Abraham, R. (1998), "Emotional dissonance in organizations: Antecedents, consequences, and moderators. Genetic, Social, and General Psychology Monographs,” 124, 229-246.

Anderson, James. C. and David. W. Gerbing (1988), "Structural Equation Modeling in Practice - a Review and Recommended 2-Step Approach," Psychological Bulletin, 103 (3), 411-23.

Ashforth, Blake. E. and Ronald. H. Humphrey (1993), "Emotional Labor in Service Roles - the Influence of Identity," Academy of Management Review, 18 (1), 88-115.

Ashkanasy, Neal. M., Charmine. E. J. Hartel, and Catherine. S. Daus (2002), “Diversity 
and Emotion: The New Frontiers in Organizational Behavior Research," Journal of Management, 28 (3), PII S0149-2063(02) 00130-7.

Bakker, Arnold. B. and Ellen Heuven (2003), "Emotional Dissonance and Burnout among Cabin Attendants," European Journal of Work and Organizational Psychology, 12 (1), 81-100.

Brotheridge, Celeste. M. and Alicia. A. Grandey (2002), "Emotional Labor and Burnout: Comparing Two Perspectives Of "People Work", Journal of Vocational Behavior, 60 (1), 17-39.

Campbell, John. P., Rodney. A. McCloy, S. H. Oppler, and C. E. Sager (1992), A Theory of Performance, San Francisco, CA: Jossey Bass.

Chau, S. L. (2007), "Examining the emotional labor process: a moderator model of emotional labor and its effects on job performance and turnover," University of Akron, Akron, Ohio.

Cho, Y., Rutherford, B., \& Park, J. (2013). "Emotional Labors Impact in a Retail Environment," Journal of Business Research. 66 (5), 670-677.

Chu, Kay Hei-Lin (2002), "The Effects of Emotional Labor on Employee Work Outcomes," Hospitality and Tourism Management, Virginia Polytechnic Institute and State University, Blacksburg, Virginia.

DeConinck, James B. (2011), “The Effects of
Leader-Member Exchange and Organizatioanl Identification on Performance and Turnover among Salespeople," Journal of Personal Selling and Sales Management, 31 (1), 21-34.

Diefendorff, James. M. and Robin. H. Gosserand (2003), "Understanding the Emotional Labor Process: A Control Theory Perspective," Journal of Organizational Behavior, 24 (8), 945-59.

Dormann, Christian., Dieter. Zapf, and Amela. Isic (2002), "Emotional Requirements at Work and Their Consequences for CallCenter Jobs," Zeitschrift Fur Arbeits-Und Organisationspsychologie, 46 (4), 205-19.

Festinger, Leon. (1956), "Personal Influence Katz, E, Lazarsfeld, Pf," Contemporary Psychology, 1 (7), 219-19.

Fisher, Cynthia D. and Neal M. Ashkanasy (2000), "The Emerging Role of Emotions in Work Life: An Introduction," Journal of Organizational Behavior, 21 (2), 123-29. Fornell, Claes. and David. F. Larcker (1981), "Evaluating Structural Equation Models with Unobservable Variables and Measurement Error," Journal of Marketing Research, 18 (1), 39-50.

Frijda, Nico. H. (1986), "The Current Status of Emotion Theory," Bulletin of the British Psychological Society, 39, A75-A75.

Glomb, Theresa. M. and M. J. Tews (2004), "Emotional Labor: A Conceptualization and Scale Development," Journal of Vocational 
Behavior, 64 (1), 1-23.

Grandey, Alicia. A. (2000), "Emotion Regulation in the Workplace: A New Way to Conceptualize Emotional Labor," J Occup Health Psychol, 5 (1), 95-110.

Grandey, A.A. (2003), "When "the show must go on": Surface acting and deep acting as determinants of emotional exhaustion and peer-rated service delivery," Academy of Management Journal, 46, 86-96.

Grandey, A. A., G. M. Fisk, \& D. D. Steiner (2005), "Must "service with a smile" be stressful? The moderating role of personal control for American and French Employees," Journal of Applied Psychology, 90, 893-904.

Gross, James. J. (1998), “Antecedent- and Response-Focused Emotion Regulation: Divergent Consequences for Experience, Expression, and Physiology," Journal of Personality and Social Psychology, 74 (1), 224-37.

Hackman, J. Richard. and Greg. R. Oldham (1975), "Development of Job Diagnostic Survey," Journal of Applied Psychology, 60 (2), 159-70.

Hair, J. F. (2006), Multivariate Data Analysis, Upper Saddle River, N.J.: Pearson Prentice Hall.

Hamwi, G. Alexander, Brian N. Rutherford, and James S. Boles (2011), "Reducing emotional exhuastion and increasing organizational support," Journal of Business and Industrial Marketing, 26 (1), 4-13.
Hatfield, Elaine., John T. Cacoppo., and Richard. L. Rapson (1994), Emotional Contagion, Cambridge [England] ; New York Hennig-Thurau, Thorsten., Markus. Groth, Michael. Paul, and Dwayne. D. Gremler (2006), "Are All Smiles Created Equal? How Emotional Contagion and Emotional Labor Affect Service Relationships," Journal of Marketing, 70 (3), 58-73.

Hobfoll, Stevan. E. (1989), "Conservation of Resources - a New Attempt at Conceptualizing Stress," American Psychologist, 44 (3), 513-24.

Hochschild, Arlie Russell (1983), The Managed Heart : Commercialization of Human Feeling, Berkeley: University of California Press.

Hollet-Haudebert, Sandrine, Jay Prakash Mulki, Christophe Fournier (2011), "Neglected Burnout Dimensions: Effect of Depersonalization and Personal Nonaccomplishment on Organizational Commitment of Salespeople," Journal of Personal Selling and Sales Management, 31 (4), 411-428.

Jaramillo, Fernando, Jay. P. Mulki, and William B. Locander (2006), "The Role of Time Wasted in Sales Force Attitudes and Intention to Quit," The International Journal of Bank Marketing, 24 (1), 24-36. and James S. Boles (2011), "Workplace Stressors, Job Attitude, and Job Behaviors: Is Interpersonal Conflict the Missing Link?" Journal of Personal 
Selling and Sales Management, 31 (3), 339-356.

Kahn, William.A. (1993). Caring for the caregivers: Patterns of organizational caregiving. Administrative Science Quarterly, 38, 539563.

Karatepe, Osman M. and Mehmet Tekinkus (2006), "The Effects of Work-family Conflict, Emotional Exhaustion and Intrinsic Motivation on Job Outcomes of Front-line Employees," International Journal of Bank Marketing, 24 (3), 173-193.

Kinman, Gail. (2009), "Emotional Labour and Strain in "Front-Line" Service Employees: Does Mode of Delivery Matter?," Journal of Managerial Psychology, 24 (2), 118-35.

Kruml, Susan. M. and Deanna. Geddes (2000), "Exploring the Dimensions of Emotional Labor," Management Communication Quarterly, 14 (1), 8-49.

Lewig, K. A. and M. F. Dollard (2001), "Social Construction of Work Stress: Australian Newsprint Media Portrayal of Stress at Work, 1997-98," Work and Stress, 15 (2), 179-90.

Locke, E.A. (1976), The Nature and Causes of Job Satisfaction, Chicago: Rand McNally. Martinez-Inigo, David., Totterdell,Peter., Carlos, Alcover.and Holman,David (2007), "Emotional Labour and Emotional Exhaustion : Interpersonal and Intrapersonal Mechanisms," Work and stress, 21 (1), 30-47.

Maslach, Christina. and Susan. E. Jackson (1981),
"The Measurement of Experienced Burnout," Journal of Occupational Behaviour, 2 (2), 99-113.

Mastracci, Sharon. H., Meredith. A. Newman, and Mary. E. Guy (2006), "Appraising Emotion Work - Determining Whether Emotional Labor Is Valued in Government Jobs," American Review of Public Administration, 36 (2), 123-38.

Menon, Kalyani. and Laurette. Dube (2000), "Ensuring Greater Satisfaction by Engineering Salesperson Response to Customer Emotions," Journal of Retailing, 76 (3), 285307.

Mills, Trudy., \& Kleinman, Sherryl. (1988). Emotions, reflexivity, and action: An interactionist analysis. Social Forces, 66, 1009-1027.

Morris, A. J. and D. C. Feldman (1996), "The Dimensions, Antecedents, and Consequences of Emotional Labor," The Academy of Management Review, 21 (4), 986-1010. (1997), "Managing Emotions in the Workplace," Journal of Managerial Issues, 9 (3), 257-274.

Nunnally, Jum. C. (1978), Psychometric Theory, New York: McGraw-Hill.

Oh, J.H., Rutherford, B., \& Park, J., (2014), "The Interplay of Salesperson's Job Performance and Satisfaction in the Financial Services Industry," Journal of Financial Service Marketing.

Pettit, John. D., Jose R. Goris., and Bobby. C. 
Vaught (1997), “An Examination of Organizational Communication as a Moderator of the Relationship between Job Performance and Job Satisfaction," Journal of Business Communication, 34 (1), 81-98.

Pugh, S. Douglas. (2001), "Service with a Smile: Emotional Contagion in the Service Encounter," Academy of Management Journal, 44 (5), 1018-27.

Pugliesi, Karen. (1999), "The Consequences of Emotional Labor: Effects on Work Stress, Job Satisfaction, and Well-Being," Motivation and Emotion, 23 (2), 125-54.

Pugliesi, Karen. and S. Shook (1997), "Gender, Jobs and Emotional Labor in a Complex Organization," Social Perspectives on Emotion, 4, 283-316.

Reichheld, F. Frederick. (1996), "Learning from Customer Defections," Harvard Business Review, 74 (2), 56-7.

Rutherford, Brian N., James S. Boles, G. Alexander Hamwi, Ramanda Madupalli, and Leann Rutherford (2009), "The Role of the Seven Dimensions of Job Satisfaction in Salesperson's Attitudes and Behaviors," Journal of Business Research, 62 (11), 1146-1151. JungKun Park, and Sang-Lin Han (2011a), "Increasing Job Performance and Decreasing Salesperson Propensity to Leave: An Examination of an Asian Sales Force," Journal of Personal Selling and Sales Management, 31 (2), 171-183. G. Alexander Hamwi, Scott B.
Friend, Nathaniel N. Hartmann (2011b), "Measuring Salesperson Burnout: A Reduced Maslach Burnout Inventory for Sales Researchers," Journal of Personal Selling and Sales Management, 31 (4), 429-440.

Saxton, Mary. J., James. S. Phillips, and Rroger. N. Blakeney (1991), “Antecedents and Consequences of Emotional Exhaustion in the Airline Reservations Service Sector," Human Relations, 44 (6), 583-95.

Shepherd, C. David, Armen Tashchian, Rick E. Ridnour (2011), “An Investigation of the Job Burnout Syndrome in Personal Selling," Journal of Personal Selling and Sales Management, 31 (4), 397-410.

Singh, J., J. R. Goolsby, \& G. K. Rhoades (1994), "Behavioral and psychological consequences of boundary spanning burnout for customer service representatives," Journal of Marketing Research, 31, 558-569.

Totterdell, Peter. and David. Holman (2003), "Emotion Regulation in Customer Service Roles: Testing a Model of Emotional Labor," Journal of Occupational Health Psycholgy, 8 (1), 55-73.

Weber, Max (1981), "Bureaucracy," in The Sociology of Organizations: Basic Studies, ed. Oscar Grusky and George A. Miller, New York: Free Press., 7-36.

Wharton, Amy. S. (1993). The affective consequences of service work. Work and $\mathrm{Oc}^{-}$ cupations, 20, 205-232.

Wharton, Amy. S. (1999), "The Psychosocial 
Consequences of Emotional Labor," Annals of the American Academy of Political and Social Science, 561, 158-76.

Wright, T. A., \& D. G. Bonett (1997), "The contribution of burnout to work performance," Journal of Organizational Behavior, 18, 491-499.

Wright, T. A., \& R. Cropanzano (1998), "Emotional exhaustion as a predictor of job performance and voluntary turnover," Journal of Applied Psychology, 83, 486-493.

Yang, Byunghwa, Youngchan Kim, Richard G. McFarland (2011), "Individual Differences and Sales Performance: a Distal-Proximal Mediation Model of Self-Efficacy, Conscientiousness, and Extraversion," Journal of Personal Selling and Sales Management, 31 (4), 371-382.

Zapf, Dieter. and Melanie. Holz (2006), "On the Positive and Negative Effects of Emotion Work in Organizations," European Journal of Work and Organizational Psychology, 15 (1), 1-28.

Claudia. Seifert, Barbara. Schmutte, Heidrun. Mertini, and Melanie. Holz (2001), "Emotion Work and Job Stressors and Their Effects on Burnout," Psychology \& Health, 16 (5), 527-45.

Zeithaml, Valerie. A., Leonard. L. Berry, and A. Parasuraman (1996), "The Behavioral Consequences of Service Quality," Journal of Marketing, 60 (2), 31-46. 